\title{
Relationship Between Halitosis and Periodontitis: a Pilot Study
}

\section{Povezanost halitoze i parodontitisa: pilot-istraživanje}

\author{
${ }^{1}$ Department of Periodontology, School of Dental Medicine, University of Zagreb, Gundulićeva 5, Zagreb, Croatia \\ Zavod za parodontologiju Stomatološkog fakulteta Sveučilišta u Zagrebu, Gundulićeva 5, Zagreb, Hrvatska \\ 2 Department of Endodontics and Restorative Dentistry, School of Dental Medicine, University of Zagreb, Gundulićeva 5, Zagreb, Croatia \\ Zavod za endodonciju i restaurativnu stomatologiju Stomatološkog fakulteta Sveučilišta u Zagrebu, Gundulićeva 5, Zagreb, Hrvatska \\ ${ }^{3}$ Undergraduate student, School of Dental Medicine, University of Zagreb, Gundulićeva 5, Zagreb, Croatia \\ Studentica 6. godine dentalne medicine Stomatološkog fakulteta Sveučilišta u Zagrebu, Gundulićeva 5, Zagreb, Hrvatska
}

\section{Abstract}

Objective: Halitosis, or oral malodour, is an unpleasant smell emanating from the oral cavity. It is a common complaint among patients with periodontitis, however, their relationship is not fully elucidated. This study aimed to evaluate the association between halitosis measures, clinical indicators of periodontitis and tongue coating, as well as a novel measure, periodontal inflamed surface area (PISA). Material and methods: Data of 10 patients with periodontitis and halitosis were included in this study. Halitosis was assessed by the organoleptic method and the portable sulphide monitor, measuring volatiles sulphur compounds. A comprehensive periodontal examination was conducted, and the parameters of probing depth, gingival recession, clinical attachment level, bleeding on probing, plaque and tongue coating were registered. The PISA was calculated using clinical attachment level, gingival recession and bleeding on probing. Results: A correlation between organoleptic score and tongue coating $(r=0.554)$ and plaque $(r=0.614)$ could be observed. No correlation between measures of halitosis and probing depth or the PISA could be detected. A significant correlation was found between organoleptic scores and volatiles sulphur compounds values $(r=0.931)$. Conclusion: This pilot study has shown and further reiterated a complex interplay between different factors causative to halitosis in patients affected by periodontitis. The results suggest that tongue coating and oral hygiene may have an important role in halitosis in patients with periodontitis.
Received: March 1. 2021

Accepted: April 27, 2021

Address for correspondence

Larisa Musić, DMD

University of Zagreb

School of Dental Medicine

Department of Periodontology

Gundulićeva 5, 10000 Zagreb, Croatia

Phone: +38514802219

Imusic@sfzg.hr

MeSH terms: Periodontal pocket; Oral Hygiene

Author keywords: Halitosis;

Periodontitis; Tongue

\section{Introduction}

Periodontitis is a chronic inflammatory disease of the tooth's supportive tissues. The complex pathogenesis of the disease involves an inflammation triggered by the main causative factor, periodontal pathogenic bacteria (1). A variety of measures have been used in both clinical and research settings for diagnosis, evaluation of the treatment outcomes and long-term monitoring, needed due to the chronic nature of the disease, i.e. periodontal probing depth, gingival recession, clinical attachment level and indices of plaque and bleeding (2). Clinical parameters (indices) of bleeding in particular, have been employed to identify and assess active inflammatory sites (3).

In 2008, Nesse et al. introduced a new measure, PISA (Periodontal Inflammed Surface Area), that reflects the surface of the bleeding epithelium of the periodontal pocket (4). The measure was initially developed as a tool that quantifies the inflamed periodontal area and, as such, assesses the inflammatory burden of periodontitis. The authors highlighted the value of PISA in the definition of periodontitis as a risk factor for other systemic diseases. This relatively new, emerging measure was hitherto correlated to the classification of periodontitis $(5,6)$ and $\mathrm{HbAlc}$ levels in healthy and diabet-
Uvod

Parodontitis je kronična upalna bolest zubnih potpornih tkiva. Složena patogeneza bolesti uključuje upalu koju pokreće glavni uzročnik - parodontne patogene bakterije (1). U kliničkim i istraživačkim uvjetima primjenjuju se razni dijagnostički postupci za dijagnozu, procjenu ishoda liječenja i dugoročno praćenje potrebno zbog kronične prirode bolesti. To su dubina sondiranja parodonta, recesija gingive, razina kliničkoga pričvrstka te indeksi plaka i krvarenja (2). Klinički parametri (indeksi) krvarenja koriste se za prepoznavanje i procjenu aktivnih upalnih mjesta (3). Nesse i suradnici predstavili su 2008. novi parametar - površinu parodonta zahvaćenu upalom - PISA-u (engl. Periodontal Inflammed Surface Area) koji se odnosi na krvareću površinu epitela parodontnog džepa (4). Taj je parametar na početku razvijen kao alat koji kvantificira upaljenu površinu parodonta i kao takav procjenjuje upalni teret (engl. inflammatory burden) parodontitisa. Autori su istaknuli vrijednost PISA-e kod parodontitisa kao čimbenik rizika za druge sistemske bolesti. Taj razmjerno novi parametar dosad je povezan s klasifikacijom parodontitisa $(5,6)$ i HbAlc kod zdravih pacijenata i dijabetičara $(7,8)$ te je izračunat za pacijente koji boluju od kronične bolesti bubrega $(9,10)$ i one s reumatoidnim artritisom (11). 
ic patients $(7,8)$ and calculated for chronic kidney disease $(9,10)$ and rheumatoid arthritis patients (11).

Halitosis is defined as an unpleasant smell emanating from the oral cavity. Quirynen et al. reported on the etiology and characteristics of 2000 patients who visited a specialised, multidisciplinary halitosis clinic in Belgium (12). Almost $80 \%$ of halitosis cases were of intra-oral origin. Tongue coating was the most common cause, followed by gingivitis/ periodontitis and a combination of the two, accounting, respectively, for $43 \%, 11 \%$ and $18 \%$ of the cases.

The olfactory malodourous compounds are primarily the endproducts of microbial degradation of both sulphurcontaining (i.e. cysteine, cystine, methionine) and non-sulphur-containing amino acids (i.e. tryptophan, lysine, ornithine). These amino acids are mainly derived from proteins present in bacterial plaque, saliva, blood and tongue coating. Volatile compounds containing sulphur (i.e. volatile sulphur compounds - VSCs), hydrogen sulphide $\left(\mathrm{H}_{2} \mathrm{~S}\right)$, methyl mercaptan $\left(\mathrm{CH}_{3} \mathrm{SH}\right)$ and dimethyl sulphide $\left[\left(\mathrm{CH}_{3}\right)_{2} \mathrm{~S}\right]$, are the major contributors to halitosis. Non-sulphur-containing volatile compounds, i.e. indole, skatole, amines and ammonia, contribute to halitosis to a lesser extent $(13,14)$.

Halitosis is a common complaint in the population of patients affected by periodontitis. Anaerobic gram-negative bacteria of the red complex, Porphyromonas gingivalis, Tanerella forsythia and Treponema denticola, strongly relate to clinical measures of periodontal disease and are also associated with higher production of VSCs $(15,16)$. However, the literature on the association between the depth of periodontal pockets and VSC production in patients with periodontitis reports conflicting data (17). Furthermore, there is a growing body of evidence that the activity of the disease, i.e. inflammation, expressed through measures of bleeding, is related to oral malodour (18-22). In patients with periodontitis, tongue coating can be another contributing factor to oral malodour since it has been reported that patients with periodontitis produce more tongue coating than healthy individuals (18).

Thus, this pilot study aims to evaluate the association between halitosis measures, clinical indicators of periodontitis and tongue coating. Furthermore, this study explores the correlation between halitosis parameters and a novel measure, periodontal inflamed surface area (PISA).

\section{Material and methods}

\section{Study subjects}

This pilot study is part of the doctoral dissertation study "Effect of probiotic Lactobacillus reuteri as an adjunct to nonsurgical treatment on halitosis of patients with periodontitis: a randomised placebo-controlled trial", approved by the Ethics Committee of the School of Dental Medicine of the University of Zagreb (05-PA-15-11/2017). The present study used baseline clinical data obtained from 10 patients who participated in the study.

Patients that were seeking or were referred for periodontal care to the Department of Periodontology of the School of Dental Medicine of the University of Zagreb were screened for possible inclusion in the study. Furthermore, a simple di-
Halitoza se definira kao neugodan vonj koji se širi iz usne šupljine. Quirynen i suradnici izvijestili su o etiologiji i karakteristikama 2000 pacijenata koji su posjetili specijaliziranu multidisciplinarnu kliniku za halitozu u Belgiji (12). Gotovo $80 \%$ slučajeva halitoze bilo je intraoralnog podrijetla. Naslage na jeziku bile su najčešći uzrok, nakon čega slijedi gingivitis/parodontitis i kombinacija gore navedenoga, odnosno prema učestalosti u $43 \%, 11 \%$ i $18 \%$ slučajeva. Spojevi neugodnog mirisa kod halitoze uglavnom su krajnji produkti mikrobne razgradnje aminokiselina i onih koji sadržavaju sumpor (tj. cistein, cistin, metionin) i aminokiselina koje ne sadržavaju sumpor (tj. triptofana, lizina ili ornitina). Te aminokiseline uglavnom potječu iz proteina u bakterijskom plaku, slini, krvi i jeziku. Hlapljivi spojevi koji sadržavaju sumpor (engl. volatile sulphur compounds - VSCs), sumporovodik $\left(\mathrm{H}_{2} \mathrm{~S}\right)$, metil-merkaptan $\left(\mathrm{CH}_{3} \mathrm{SH}\right)$ i dimetilni sulfid $\left[\left(\mathrm{CH}_{3}\right)_{2} \mathrm{~S}\right]$ glavni su uzročnici halitoze. Hlapljivi spojevi koji ne sadržavaju sumpor, tj. indol, skatol, amini i amonijak, pridonose halitozi u manjoj mjeri $(13,14)$.

Pacijenti s dijagnozom parodontitisa učestalo se žale na halitozu. Anaerobne gram-negativne bakterije crvenoga kompleksa - Porphyromonas gingivalis, Tanerella forsythia i Treponema denticola - snažno su povezane s kliničkim vrijednostima parodontitisa te $s$ većom produkcijom VSC-a $(15,16)$. No u literaturi postoje oprečni podatci o povezanosti dubine parodontnih džepova i stvaranja VSC-a kod pacijenata s parodontitisom (17). Nadalje, sve je više dokaza da je aktivnost bolesti, tj. upala izražena u vrijednostima krvarenja, povezana sa zadahom $(18-22)$. Kod pojedinaca s parodontitisom naslage na jeziku mogu biti još jedan čimbenik koji pridonosi neugodnom zadahu, jer je zabilježeno da takvi pacijenti imaju više naslaga na jeziku nego zdrave osobe (18).

Dakle, ovim pilot-istraživanjem želi se procijeniti povezanost između mjera halitoze, kliničkih pokazatelja parodontitisa i naslaga na jeziku. Cilj je također istražiti vezu između parametara halitoze i površine parodonta zahvaćene upalom (PISA).

\section{Materijali i metode}

\section{Sudionici}

Ovo pilot-istraživanje dio je istraživanja u sklopu doktorske disertacije „Učinak probiotika Lactobacillius reuteri kao dodatne terapije uz nekirurško liječenje halitoze kod bolesnika s parodontitisom - randomizirano placebom kontrolirano ispitivanje "koju je odobrilo Etičko povjerenstvo Stomatološkog fakulteta Sveučilišta u Zagrebu (05-PA-15-11/2017). U ovom su se istraživanju koristili početni klinički podatci 10 pacijenata uključenih u istraživanje.

Pacijenti koji su tražili ili su upućeni na parodontnu terapiju u Zavod za parodontologiju Stomatološkog fakulteta Sveučilišta u Zagrebu pregledani su radi mogućeg uključivanja u istraživanje. Nadalje, korištena je jednostavna dihoto- 
chotomous organoleptic assessment (halitosis present / not present) was employed as a preliminary screening method for halitosis. A thorough medical and dental history was then taken, following the recommendations from an international workshop consensus (25) to exclude extraoral halitosis, causative of systemic diseases and/or medications.

Inclusion criteria were: 1) Systemically healthy patients of both genders; 2) Non-smokers; 3) Presenting at least 20 teeth; 4) Untreated moderate to advanced generalised chronic periodontitis according to the 1999 Classification (23) / Generalised periodontitis stage II-IV according to the 2017 Classification (24); 4) Halitosis of intraoral origin, with a level of total sulphur compounds concentration - tVSC $\geq 160$ parts per billion (ppb) measured with a portable sulphide monitor (Halimeter ${ }^{\circ}$, Interscan Corporation Chatsworth, CA, USA).

Exclusion criteria were 1) Pregnant and lactating females; 2) Antibiotics received for dental or non-dental purposes within 6 months before the start of the study; 3) Presence of systemic diseases or the use of medication that may affect periodontal tissues, the parameter of bleeding that can be the cause of extra-oral malodour; 4) Acute oral or periodontal inflammation or infection (i.e. pericoronitis, necrotising periodontal diseases, etc.)

A comprehensive periodontal examination was performed by a single, calibrated periodontist (L.M.) The following parameters were measured and registered using a UNC-15 periodontal probe (Hu Friedy, Chicago, IL, USA): periodontal pocket depth (PPD), plaque (calculated as fullmouth plaque score - FMPS), bleeding on probing (calculated as full-mouth bleeding score - FMBS) and gingival recession (REC). A periodontal assessment of the parameters was done at 6 sites per tooth, excluding third molars due to the high prevalence of agenesis, absence due to extraction, malpositioning or infraocclusion, which may present difficulties in measuring periodontal parameters.

\section{Halitosis assessment}

Halitosis assessment was performed using an organoleptic method and a portable sulphide monitor, measuring tVSC, i.e. total concentration of the 3 sulphur compounds hydrogen sulphide, methyl mercaptan and dimethyl sulphide (Halimeter ${ }^{\circ}$, Interscan Corporation Chatsworth, CA, USA). Both procedures were performed following recommendations from the literature (26) and the manufacturer's instructions for the use of device (27). Patients were requested to refrain from eating spicy food, onion and garlic at least 24 hours before the assessment. Furthermore, they were asked not to use scented oral hygiene products on the morning of and have breakfast at least 2 hours before the measurement. All of the measurements were made in the morning, between 08:00 and 11:00 a.m.

The organoleptic assessment and scoring were done by a single clinician (L.M.) The participant was asked to keep the mouth closed for $2 \mathrm{~min}$ and breathe through the nose. The examiner positioned approximately $5-10 \mathrm{~cm}$ from the participant's mouth, scored the breath with the mouth open while the patient was slowly exhaling the breath. Malodour was given an organoleptic score (OLS) from 0 to 5 as follows: mna organoleptička procjena (halitoza prisutna / nije prisutna) kao preliminarna metoda probira za halitozu. Zatim je uzeta detaljna medicinska i stomatološka anamneza, slijedeći preporuke konsenzusa međunarodne radionice (25) kako bi se isključila ekstraoralna halitoza prouzročena sustavnim bolestima i/ili lijekovima..

Kriteriji za uključivanje bili su: 1) Sistemski zdravi pacijenti obaju spolova; 2) Nepušači; 3) Prisutnost najmanje 20 zuba; 4) Neliječeni umjereni do uznapredovali generalizirani kronični parodontitis prema Klasifikaciji iz 1999. godine (23) / Generalizirani parodontitis stadij II - IV prema Klasifikaciji iz 2017. godine (24); 4) Halitoza intraoralnog podrijetla s razinom koncentracije ukupnih sumpornih spojeva tVSC $\geq 160$ dijelova na milijardu (ppb), izmjerena prijenosnim sulfidnim monitorom (Halimeter ${ }^{\circ}$, Interscan Corporation Chatsworth, CA, SAD).

Kriteriji za isključenje bili su: 1) Trudnice i dojilje; 2) Antibiotici uzeti u stomatološke ili nestomatološke svrhe 6 mjeseci prije početka istraživanja; 3) Sustavne bolesti ili uporaba lijekova koji mogu utjecati na parodontna tkiva, parametar krvarenja ili ekstraoralni uzroci zadaha; 4) Akutna oralna ili parodontna upala ili infekcija (tj. perikoronitis, nekrotizirajuće parodontne bolesti itd.).

Sveobuhvatan parodontni pregled obavio je jedan kalibrirani parodontolog (L. M.). Sljedeći parametri izmjereni su i registrirani parodontnom sondom UNC-15 (Hu Friedy, Chicago, IL, SAD): dubina parodontnog džepa (PPD), plak (izračunato kao prisutnost plaka na razini cijelih usta FMPS), krvarenje pri sondiranju (izračunato kao krvarenje na razini cijelih usta - FMBS) i recesija gingive (REC). Parodontna procjena parametara provedena je na šest mjesta po zubu, isključujući treće kutnjake zbog velike prevalencije njihove ageneze, odsutnosti zbog ekstrakcije i malpozicije ili infraokluzije, što može činiti poteškoće u mjerenju parodontnih parametara.

\section{Procjena halitoze}

Procjena halitoze provedena je organoleptičkom metodom i prijenosnim sulfidnim monitorom mjereći tVSC, tj. ukupnu koncentraciju triju spojeva sa sumporom - vodikova sulfida, metil-merkaptana i dimetilnog sulfida (Halimeter ${ }^{\circ}$, Interscan Corporation Chatsworth, CA, SAD). Oba postupka obavljena su prema preporukama iz literature (26) i proizvođača uređaja (27). Od pacijenata je zatraženo da se suzdrže od konzumiranja začinjene hrane, luka i češnjaka najmanje 24 sata prije procjene. Nadalje, zamoljeni su da se ujutro na dan pregleda ne koriste mirisnim proizvodima za oralnu higijenu i doručkuju najmanje dva sata prije mjerenja. Sva mjerenja obavljena su između 8 i 11 sati.

Organoleptičku procjenu i bodovanje obavio je jedan kliničar (L. M.). Sudionika je zamolio da drži usta zatvorena dvije minute i diše kroz nos. Ispitivač se nalazio od 5 do 10 $\mathrm{cm}$ od usta sudionika te je ocijenio dah iz otvorenih usta te dok je pacijent polako izdisao. Zadah je organoleptički ocijenjen (OLS) od 0 do 5: 0 - nema zamjetnog mirisa; 1 - vonj se jedva osjeća; 2 - vonj je blag, ali se jasno osjeća; 3 - umjeren vonj; 4 - jak vonj; 5 - izniman smrad prema Rosenbergu i suradnicima (28). 
0: no appreciable odour; 1: barely noticeable odour; 2 : slight, but clearly noticeable odour; 3: moderate odour; 4: strong odour; and 5: extremely foul odour, as described by Rosenberg et al. (28).

The measurement of the tVSC (total volatile sulfur compounds) concentration, expressed as parts per billion, was obtained using the portable sulphide monitor. A disposable tube was inserted approximately $3-4 \mathrm{~cm}$ into the participant's mouth, slightly opened, without touching any of the oral surfaces. 3 consecutive measurements were taken, and the mean of the measurements was recorded (Figure 1).

\section{Tongue coating evaluation}

The tongue coating (TC) assessment was done using the Winkel Tongue Coating Index (WTCI) (29). The dorsum of the tongue was divided into six areas, three in the anterior portion and three in the posterior portion, and each area was then assigned one of the three possible scores. No coating was scored as 0 , light coating as 1 and heavy coating as 2 , with a total tongue score ranging from 0 to 12 .

\section{PISA calculation}

PISA was calculated using an available calculator within an Excel spreadsheet, prepared by the authors Nesse et al. (4) and uploaded on the website www.parsprototo.info for research use. The calculation was done in 7 steps, previously reported in detail by the authors. In short: 1) Mean clinical attachment level (CAL) was calculated for each tooth after data input; 2) Calculated mean CAL was translated into attachment loss surface area (ALSA) for each tooth with an appropriate formula; 3) Mean recession was calculated for each tooth after data input; 4) Calculated mean recession was translated into recession surface area (RSA) for each tooth with an appropriate formula; 5) RSA was subtracted from ALSA for each tooth, calculating periodontal epithelial surface area (PESA); 6) PESA of each tooth was multiplied by the proportion of positive $\mathrm{BOP}$ sites of that tooth, rendering periodontal inflamed surface area (PISA); 7) Total PISA was calculated through the sum of PISAs of each individual tooth.

\section{Data analysis}

The normality of distribution was evaluated using the Shapiro-Wilk test and by inspecting normal Q-Q plots. Due to identified departures from normality, data were presented as medians and interquartile ranges. A non-parametric correlation analysis (Spearman) was used to explore the relationship between variables PISA, FMBS, FMPS, PPD $\geq 4 \mathrm{~mm}$, $P P D \geq 6 \mathrm{~mm}$, tVSC, OLS, and TC. The statistical analysis was performed using SPSS (version 20, IBM, Armonk, NY, USA). Due to exploratory nature of this pilot study, the level of significance was set at $\alpha=0.1$ (30).

\section{Results}

\section{General results}

A total of 10 participants, 5 male and 5 female, were included in this pilot study. The median age was 38.5 (range
Mjerenje koncentracije tVSC-a (ukupnih hlapljivih sumpornih spojeva), izraženo u dijelovima na milijardu, učinjeno je s pomoću prijenosnoga sulfidnog monitora. Jednokratna mjerna cjevčica umetnuta je od 3 do $4 \mathrm{~cm}$ u sudionikova usta koja su bila minimalno otvorena, bez dodirivanja bilo koje površine usne šupljine. Učinjena su tri uzastopna mjerenja i zabilježena je srednja vrijednost mjerenja (slika 1.).

\section{Procjena naslaga na jeziku}

Procjena obloženosti, tj. naslaga na jeziku (TC) provedena je s pomoću Winkelova indeksa obloženosti jezika (WTCI) (29). Dorzum jezika podijeljen je na šest područja - tri u prednjem i tri u stražnjem dijelu, a svakom se području zatim dodijelio jedan od triju mogućih rezultata. Ako nema naslaga, ocjena je 0 , mala količina naslaga znači ocjenu 1 , a velika količina ocjenu 2, s ukupnim rezultatom u rasponu od 0 do 12.

\section{Izračun PISA vrijednosti}

PISA je izračunata korištenjem dostupnog kalkulatora u proračunskoj tablici Excel koju su pripremili autori Nesse i suradnici (4) i koja je postavljena na mrežnu stranicu www.parsprototo.info radi primjene u istraživanjima. Izračun se obavlja u sedam koraka, što su autori prethodno detaljno objasnili. Ukratko: 1) Prosječna razina kliničkoga pričvrstka (CAL) izračunava se za svaki zub nakon unosa podataka; 2) Izračunata srednja vrijednost CAL-a pretvara se u površinu gubitka pričvrstka (ALSA) za svaki zub s odgovarajućom formulom; 3) Prosječna recesija izračunava se za svaki zub nakon unosa podataka; 4) Izračunata srednja vrijednost recesije prevodi se u površinu recesije (RSA) za svaki zub s odgovarajućom formulom; 5) RSA se oduzima od ALSA-e za svaki zub, računajući površinu parodontnog epitela (PESA); 6) PESA svakog zuba množi se $s$ brojem pozitivnih BOP mjesta toga zuba, što čini upaljenu parodontnu površinu (PISA); 7) Ukupna PISA izračunava se na temelju zbroja PISA-e svakoga zuba.

\section{Analiza podataka}

Normalnost raspodjele procijenjena je Shapiro-Wilkovim testom i ispitivanjem normalnih Q-Q ploha. Zbog utvrđenih odstupanja od normalnoga, podatci su predstavljeni kao medijani i interkvartilni rasponi. Neparametijska korelacijska analiza (Spearman) korištena je za istraživanje odnosa između varijabli PISA, FMBS, FMPS, PPDn $\geq 4 \mathrm{~mm}, \mathrm{PPD} \geq 6 \mathrm{~mm}$, tVSC, OLS i TC. Statisticka analiza provedena je s pomoću SPSS-a (verzija 20, IBM, Armonk, NY, SAD). Zbog eksploratorne prirode ovoga pilot-istraživanja razina značajnosti postavljena je na $\alpha=0,1(30)$.

\section{Rezultati}

\section{Opći rezultati}

Ukupno 10 sudionika - 5 muškaraca i 5 žena - bilo je uključeno u ovo pilot-istraživanje. Srednja dob bila je 38,5 


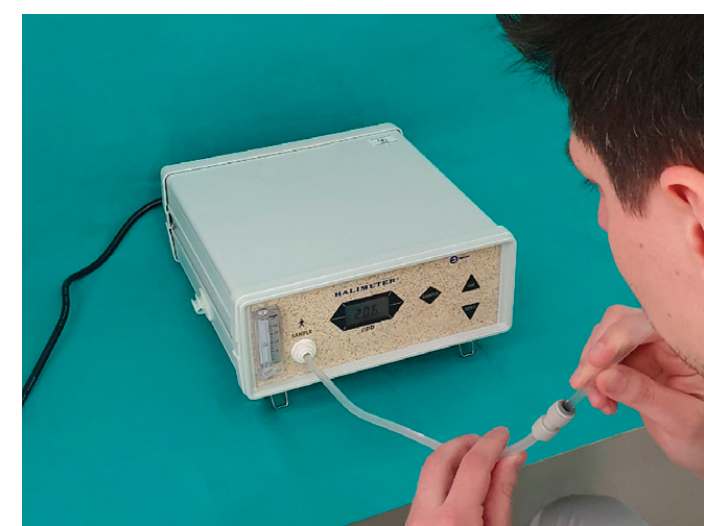

Figure 1 Use of Halimeter $®$, Interscan Corporation Chatsworth, CA, USA in the clinical setting

Slika 1. Upotreba instrumenta Halimeter $®$ (Interscan Corporation Chatsworth, CA, SAD) u ordinaciji dentalne medicine

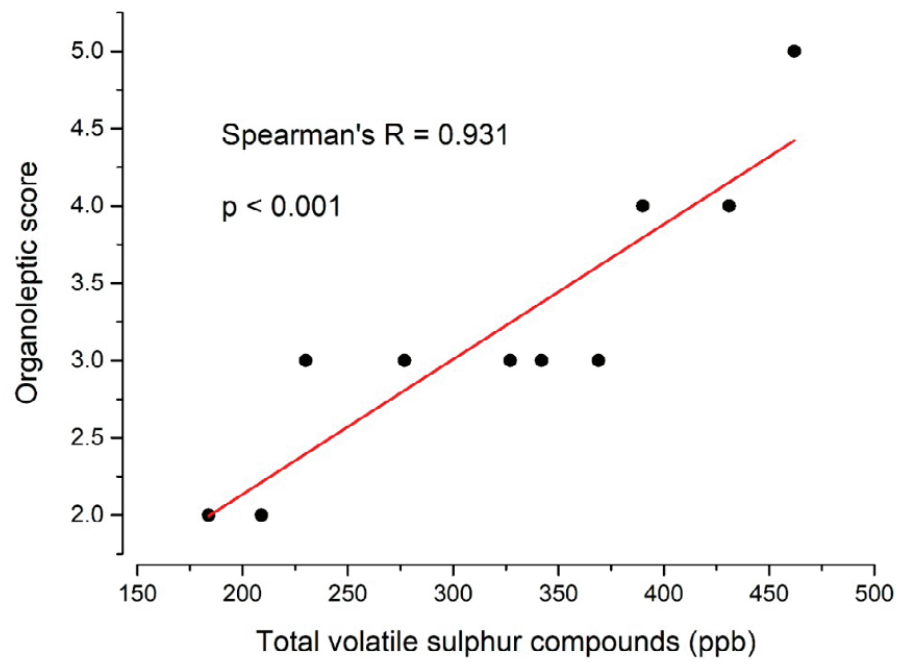

Figure 2 Correlation between the organoleptic score and total volatile sulphur compounds

Slika 2. Korelacija između organoleptičke ocjene i ukupnih hlapljivih sumpornih spojeva
29 - 72). The median, minimum and maximum, and interquartile range of the measured parameters are listed in Table 1. The median PISA value was 1617.8. The halitosis measures median values, OLS and tVSC were 3.0 and 334.5 , respectively. The median tongue coating value was 5.0.

\section{Correlations between different parameters}

In terms of the association between the clinical and halitosis measures, significant correlations were found between the OLS and FMPS ( $\mathrm{r}=0.614, \mathrm{p}=0.059)$, as well as between the OLS and TC ( $\mathrm{r}=0.554, \mathrm{p}=0.097)$ (Table 2). A significant correlation was found between OLS and tVSC values, $\mathrm{r}=0.931, \mathrm{p}<0.001$ (Figure 2).

In addition, the PISA values showed a positive correlation with FMBS and FMPS indices, $r=0.733, \mathrm{p}=0.016$ and $\mathrm{r}=0.839 ; \mathrm{p}=0.002$, respectively. (raspon 29 - 72). Medijan, minimum i maksimum te interkvartilni raspon izmjerenih parametara navedeni su u tablici 1. Medijan vrijednosti PISA-e bio je 1617,8. Srednje vrijednosti mjerenja halitoze - OLS i tVSC, iznosile su 3,0, odnosno 334,5. Srednja vrijednost naslaga na jeziku bila je 5,0.

\section{Povezanost između različitih parametara}

Kad je riječ o povezanosti kliničkih mjera i mjera halitoze, pronađene su značajne korelacije između OLS-a i FMPS-a $(r$ $=0,614, \mathrm{p}=0,059)$ te između OLS-a i TC-a $(\mathrm{r}=0,554, \mathrm{p}=$ 0,097 ) (tablica 2.). Pronađena je značajna korelacija između vrijednosti OLS-a i tVSC-a, $\mathrm{r}=0,931, \mathrm{p}<0,001$ (slika 2.).

Uz to su vrijednosti PISA-e pokazale pozitivnu korelaciju $s$ indeksima FMBS i FMPS, $r=0,733, p=0,016$ i $r=0,839$; $\mathrm{p}=0,002$.

Table 1 Median, minimum and maximum, and interquartile range of age, clinical periodontal measures, halitosis measures and tongue coating

Tablica 1. Medijan, minimum i maksimum te interkvartilni raspon dobi, kliničkih parodontnih parametara, parametara halitoze i naslaga na jeziku

\begin{tabular}{l|c|c|c|c} 
& Median $\bullet$ Medijan & Minimum & Maximum • Maksimum & $\begin{array}{c}\text { Interquartile range } \\
\text { Interkvartilni raspon }\end{array}$ \\
\hline Age $\bullet$ Dob (y) & 38.5 & 29.0 & 72.0 & 12.0 \\
\hline PISA (mm $\left.{ }^{2}\right)$ & 1617.8 & 1248.6 & 2950.7 & 934.4 \\
\hline FMBS (\%) & 78.0 & 61.9 & 100.0 & 25.4 \\
\hline FMPS (\%) & 82.9 & 75.0 & 100.0 & 17.6 \\
\hline PPD $\geq \mathbf{4 m m}(\mathbf{N})$ & 57.0 & 41.0 & 111.0 & 53.0 \\
\hline PPD $\geq \mathbf{6 m m}(\mathbf{N})$ & 14.5 & 0.0 & 63.0 & 17.0 \\
\hline tVSC (ppb) & 334.5 & 184.0 & 462.0 & 176.0 \\
\hline OLS (N) & 3.0 & 2.0 & 5.0 & 1.0 \\
\hline TC (N) & 5.0 & 1.0 & 10.0 & 4.0 \\
\hline
\end{tabular}

PISA - periodontal inflamed surface area $\bullet$ površina parodontne upale; FMBS - full-mouth bleeding score $\bullet$ iznos krvarenja na razini cijelih usta; FMPS - full-mouth plaque score $\bullet$ iznos plaka na razini cijelih usta; $\mathrm{PPD} \geq 4 \mathrm{~mm}$ - pocket probing depth $\geq 4 \mathrm{~mm} \bullet$ dubina sondiranja parodontnog džepa $\geq 4$ $\mathrm{mm} ; \mathrm{PPD} \geq 6 \mathrm{~mm}$ - pocket probing depth $\geq 6 \mathrm{~m} \bullet$ dubina sondiranja parodontnog džepa $\geq 6 \mathrm{~mm} \mathrm{~m}$; tVSC - total volatile sulphur compounds, measured with Halimeter $\bullet$ ukupni hlapljivi sumporni spojevi izmjereni instrumentom Halimeter ${ }^{\bullet}$; OLS - organoleptic score • organoleptička ocjena; TC tongue coating $\bullet$ obloženost (naslage) jezika 
Table 2 Correlation between different parameters

Tablica 2. Korelacija između različitih parametara

\begin{tabular}{|c|c|c|c|c|c|c|c|c|}
\hline & PISA & FMBS & FMPS & $P P D \geq 4 \mathrm{~mm}$ & $P P D \geq 6 \mathrm{~mm}$ & tVSC & OLS & $\mathrm{TC}$ \\
\hline PISA & - & $0.733(0.016)$ & $0.839(0.002)$ & $0.572(0.084)$ & $0.697(0.025)$ & - & - & - \\
\hline FMBS & - & - & $0.742(0.014)$ & $0.652(0.041)$ & - & - & - & - \\
\hline $\mathrm{PPD} \geq 4 \mathrm{~mm}$ & - & - & - & - & - & - & - & - \\
\hline$P P D \geq 6 \mathrm{~mm}$ & - & - & - & - & - & - & - & - \\
\hline tVSC & - & - & - & - & - & - & $0.931(0.000)$ & - \\
\hline OLS & - & - & - & - & - & - & - & $0.554(0.097)$ \\
\hline $\mathrm{TC}$ & - & - & - & - & - & - & - & - \\
\hline
\end{tabular}

Values $\bullet$ Vrijednosti: Spearman's correlation coefficient - $r$ (p-values) $\bullet$ Spearmanov koeficijent korelacije $-r$ ( $p$-vrijednosti)

PISA - periodontal inflamed surface area $\bullet$ površina parodontne upale; FMBS - full-mouth bleeding score $\bullet$ iznos krvarenja na razini cijelih usta; FMPS - full-mouth plaque score $\bullet$ iznos plaka na razini cijelih usta; $P P D \geq 4 \mathrm{~mm}$ - pocket probing depth $\geq 4 \mathrm{~mm} \bullet$ dubina sondiranja parodontnog džepa $\geq 4$ $\mathrm{mm} ; \mathrm{PPD} \geq 6 \mathrm{~mm}$ - pocket probing depth $\geq 6 \mathrm{~m} \bullet$ dubina sondiranja parodontnog džepa $\geq 6 \mathrm{~mm} \mathrm{~m}$; tVSC - total volatile sulphur compounds, measured with Halimeter ${ }^{\circ}$ ukupni hlapljivi sumporni spojevi izmjereni instrumentom Halimeter ${ }^{\circledR}$; OLS - organoleptic score • organoleptička ocjena; TC tongue coating $\bullet$ obloženost (naslage) jezika

\section{Discussion}

The present pilot study explored the correlation between the parameters of halitosis and clinical indicators of periodontitis, tongue coating and, for the first time, the PISA.

Rizzo (31) and Tonzetich (32) were among the first to report a correlation between the production of sulfur compounds and periodontal disease, particularly the presence of periodontal pockets. While other research groups published similar findings, the correlation between the halitosis parameters and periodontal pocket depth was not always exclusive. A study by Liu et al., on a large population of 2000 participants, reported a significant correlation between the OLS and tVSC levels and pocket depth, however, tongue coating was highlighted as the most significant variable related to the oral malodour measures (19). Yaegaki \& Sanada (18) showed the association between a higher concentration of methyl mercaptan in patients with pocket depths above $4 \mathrm{~mm}$ and bleeding on probing. The severity of periodontitis correlated with halitosis as reported by Söder et al. (33), as well as measures of oral hygiene, expressed through plaque and calculus indices. In our study, however, the number of pockets above $4 \mathrm{~mm}$ and $6 \mathrm{~mm}$, respectively, showed no significant correlation with halitosis measures.

It is important to emphasize the fact that not all evidence supports the existence of correlation between the number of periodontal pockets and depth with halitosis measures, thus questioning the causative relationship between periodontitis and halitosis. Bosy et al. (34) found a correlation between tongue coating and floss odour after insertion in the interdental area with tVSC and OLS values. However, no significant difference in halitosis measures could be observed among patients with periodontitis and healthy groups of participants. In the present study, an association between OLS and FMPS was also observed. While the indices measuring plaque, i.e. oral hygiene, are not the same as ours and the abovementioned study, it has been suggested in the literature that poor oral hygiene could be a source of halitosis of patients with periodontitis irrespective of the presence of periodontal pockets (35).

\section{Rasprava}

Autori ovog pilot-projekta istraživali su korelaciju između parametara halitoze i kliničkih parametara parodontitisa, obloženosti jezika i, prvi put, PISA-e.

Rizzo (31) i Tonzetich (32) među prvima su izvijestili o povezanosti između stvaranja sumpornih spojeva i parodontne bolesti, odnosno prisutnosti parodontnih džepova. Iako su druge istraživačke skupine to potvrđivale, povezanost između parametara halitoze i dubine parodontnog džepa nije uvijek bila jedinstvena. Istraživanje Liua i suradnika, na velikoj populaciji od 2000 sudionika, pokazalo je da je riječ o značajnoj korelaciji između razine OLS-a i tVSC-a i dubine džepa, međutim obloženost jezika istaknuta je kao najznačajnija varijabla povezana s oralnim vrijednostima zadaha (19). Yaegaki i Sanada (18) istaknuli su povezanost veće koncentracije metil-merkaptana kod pacijenata s dubinom džepa iznad $4 \mathrm{~mm}$ i krvarenjem pri sondiranju. Kako su izvijestili Söder i suradnici (33), uznapredovalost parodontitisa korelirala je $s$ halitozom, ali i s vrijednostima oralne higijene izraženima kroz indekse plaka i kamenca. No u našem istraživanju broj džepova iznad $4 \mathrm{~mm}$, odnosno $6 \mathrm{~mm}$, nije pokazao značajnu korelaciju s vrijednostima halitoze.

Važno je istaknuti da svi dokazi ne podupiru povezanost broja i dubine parodontnih džepova s vrijednostima halitoze, čime se dovodi u pitanje uzročni odnos između parodontitisa i halitoze. Bosy i suradnici (34) pronašli su korelaciju između naslaga na jeziku i mirisa zubnog konca nakon umetanja u međuzubno područje s vrijednostima tVSC-a i OLS-a. No nije se mogla uočiti značajna razlika u jačini halitoze između pacijenata s parodontitisom i zdravih sudionika. U ovom istraživanju zapažena je i povezanost između OLS-a i FMPSa. Iako indeksi kojima se mjeri plak, tj. oralna higijena, nisu jednaki u ovom i prije spomenutom istraživanju, u literaturi se sugerira da bi loša oralna higijena mogla biti izvor halitoze kod bolesnika s parodontitisom, bez obzira na parodontne džepove (35).

Calil i suradnici te De Boever i Loesche $(36,37)$ izvijestili su o povezanosti između halitoze i količine naslaga na jeziku, ali ne i o uznapredovalosti parodontitisa. Presječna istraživa- 
Calil et al. and De Boever \& Loesche $(36,37)$ reported an association between halitosis and tongue coating measures, yet not with periodontal disease measures.

As seen in the general population-based cross-sectional studies $(12,19,20)$, tongue coating is suggested to be the primary cause of halitosis among periodontally healthy subjects. This is primarily attributed to the large surface of the tongue's dorsum and its morphology (38), thus contributing to the accumulation of dead microbial and host cells, the source of halitosis. Furthermore, taking into account the evidence highlighted hitherto, it has been suggested that tongue coating is also an important contributing factor to halitosis in patients with periodontitis, since they produce more tongue coating than healthy individuals (39). They also harbour greater counts of the VSC-producing periodontal pathogen, Porphyromonas gingivalis, on the dorsum of the tongue (40). Our study showed a correlation between tongue coating and OLS values, but not tVSC. While sulphide monitors such as Halimeter ${ }^{\circ}$ and OralChroma ${ }^{\mathrm{TM}}$ are an objective measuring of $\mathrm{tVSCs}$ and previous studies confirmed their clinical value, they fail to capture the contributions of non-sulfur compounds to the overall halitosis $(14,41,42)$. An organoleptic assessment is considered the gold standard for halitosis detection because the human nose can evaluate a greater variety of malodourous compounds/odourants (41). According to the manufacturer of the Halimeter, patients are diagnosed with halitosis when the level of tVSCs exceeds $160 \mathrm{ppb}$, but as suggested by Vandekerckhove et al. (41) this cut-off should be lowered in order to improve the sensitivity of the instrument with regard to organoleptic testing. The range of OLS and $\mathrm{tVSC}$ values in our study ranged from 2 - 5 and 184.0 $462.0 \mathrm{ppb}$, respectively, and a strong correlation was found between the two halitosis variables $(r=0.931)$. This is considered an important finding, considering that this pilot study was performed as a preliminary investigation for the upcoming comprehensive study "Effect of probiotic Lactobacillus reuteri as an adjunct to nonsurgical treatment on halitosis of patients with periodontitis: a randomised placebo-controlled trial", in which halitosis measurements will be done by OLS assessment, and Halimeter as an adjunct.

As indicated before, bleeding expressed through various bleeding and inflammation indices was found to be correlated to halitosis in several published studies $(18,19,21,43,44)$. Bleeding is a sign of inflammation of the connective tissue of the gingiva. Thus, a variety of bleeding indices are employed to assess the presence of inflammation. In particular, when bleeding is associated with pocket probing, it indicates a site with active periodontal disease $(3,45)$. A possible explanation for the association of bleeding pockets and halitosis is the presence of periodontal pathogens, VSC-producing anaerobic bacteria at such sites (46). Indeed, as highlighted in a study by Torresyap et al., intra-pocket sulfide levels, measured with a specific Diamond Probe/Perio 2000 system, are higher in deeper pockets with higher counts of orange- and red-complex bacteria (47). Since PISA is a parameter that quantifies the surface of the bleeding epithelium of the pocket, one of the hypotheses of this study was that a correlation between this novel measure and halitosis might be observed. nja u općoj populaciji $(12,19,20)$ sugeriraju da je obloženi jezik primarni uzrok halitoze kod parodontno zdravih ispitanika. To se u prvom redu pripisuje velikoj površini dorzuma jezika i njegovoj morfologiji (38), što pridonosi nakupljanju mrtvih mikrobnih stanica i stanica domaćina, izvora halitoze. Nadalje, uzimajući u obzir dosadašnje dokaze, smatra se da je obloženi jezik također važan čimbenik koji pridonosi halitozi kod pacijenata s parodontitisom, jer takvi pacijenti i stvaraju više naslaga na jeziku nego zdrave osobe (39). Također imaju veći broj parodontopatogena koje proizvodi VSC, Porphyromonas gingivalis, na dorzumu jezika (40). Naše je istraživanje pokazalo korelaciju između naslaga na jeziku i vrijednosti OLS-a, ali ne i tVSC-a. Iako sulfidni monitori poput Halimetera i OralChroma ${ }^{\text {Tx }}$ služe za objektivno mjerenje tVSCa, a dosadašnja istraživanja potvrdila su njihovu kliničku vrijednost, oni ne uspijevaju zabilježiti doprinos nesumpornih spojeva u ukupnoj halitozi $(14,41,42)$. Kao takva, organoleptička procjena smatra se zlatnim standardom za otkrivanje halitoze zato što ljudski nos može procijeniti veću raznolikost spojeva koji pridonose vonju iz usta (41). Prema uputama proizvođača Halimetra, pacijentima se dijagnosticira halitoza kada razina tVSC-a prelazi 160 ppb, ali kako su predložili Vandekerckhove i suradnici (41), tu bi graničnu vrijednost trebalo smanjiti kako bi se poboljšala osjetljivost instrumenta s obzirom na organoleptička ispitivanja. Raspon vrijednosti OLS-a i tVSC-a u našem istraživanju kretao se između 2 i 5 te 184,0 i 462,0 ppb, i utvrđena je snažna korelacija između tih dviju varijabli halitoze $(\mathrm{r}=0,931)$. To se smatra važnim nalazom $s$ obzirom na to da je pilot-istraživanje provedeno kao preliminarno za buduće sveobuhvatno istraživanje „Učinak probiotika Lactobacillius reuteri kao dodatne terapije uz nekirurško liječenje na halitozu kod pacijenata s parodontitisom - randomizirano placebom kontrolirano ispitivanje" u kojemu će se mjerenje halitoze obavljati OLS-om, a mjerni instrument Halimeter ${ }^{\circ}$ koristit će se kao dodatni.

Kao što je već istaknuto, u nekoliko objavljenih istraživanja utvrđeno je da je krvarenje, izraženo različitim indeksima krvarenja i upale, povezano s halitozom $(18,19,21,43$, 44). Krvarenje je znak upale vezivnoga tkiva gingive i zato se za procjenu upale upotrebljavaju različiti indeksi krvarenja. Konkretno, kada je krvarenje povezano sa sondiranjem parodontnih džepova, to upućuje na mjesto $s$ aktivnom parodontnom bolešću $(3,45)$. Moguće objašnjenje povezanosti džepova koji krvare i halitoze jest prisutnost parodontopatogena, anaerobnih bakterija koje proizvode VSC na takvim mjestima (46). Kao što je istaknuto u studiji Torresyapa i suradnika, razine sulfidnih spojeva unutar džepa izmjerene specifičnim sustavom Diamond Probe / Perio 2000 veće su u dubljim džepovima s većim brojem bakterija narančastoga i crvenoga kompleksa (47). Kako je PISA parametar koji kvantificira površinu epitela džepa koji krvari, jedna od hipoteza ovog istraživanja bila je da se može uočiti povezanost između te mjere i halitoze. No istraživanje nije potvrdilo tu hipotezu jer nije ustanovljena povezanost $s$ vrijednostima OLSa ili tVSC-a. Ipak, vrijednosti PISA-e pozitivno su povezane s vrijednostima FMPS-a i FMBS-a, kao što su već izvijestili Park i suradnici (5). Leira i suradnici te Nesse i suradnici (4, 6) povezali su vrijednosti PISA-e i parodontni status, ističu- 
However, the present study did not confirm this hypothesis since no significant observations with OLS or tVSC values were found. Nonetheless, the PISA values were positively correlated to values of FMPS and FMBS, as previously reported by Park et al. (5).

Leira et al. and Nesse et al. $(4,6)$ correlated the PISA values and periodontal status, highlighting the increase in PISA values with disease severity, the former also suggesting a cutoff PISA value of $\geq 130.33 \mathrm{~mm}^{2}$ as a predictor for the presence of periodontitis. In our study, the values of PISA ranged from 1248.6 to $2950.7 \mathrm{~mm}^{2}$. These values correspond to the values calculated for severe periodontitis (6).

The intrinsic limitations of this pilot study are the small sample size and the absence of a control group. Due to the sample of $\mathrm{n}=10$ representing a specific population of patients, i.e. only highly inflamed patients with a progressed periodontitis forms and identifiable intraoral halitosis, the analysis might not have captured the correlation between all of the parameters. A sequel study with a larger sample size will be performed, including a control group of patients with periodontitis and no halitosis.

\section{Conclusion}

This pilot study shows and further reiterates a complex interplay between different factors causative to halitosis in patients affected by periodontitis. OLS values correlated to measures of oral hygiene and tongue coating, however, no correlation to probing depth could be observed.

\section{Conflict of interest}

None declared

Contributions: L.M. - primary clinical investigator, data collection, concept and design, interpretation, visualisation, writing, approval of the article for publication; M.P. - concept and design, formal analysis, statistical analysis, interpretation, writing; J.P. - data collection, visualisation, writing; A.B. - interpretation, writing, critical review; D.P. - supervision, critical review and editing, approval of the article for publication; I.P. - clinical research operator, concept and design, interpretation, writing, critical review and editing. ći porast vrijednosti PISA-e s progresijom bolesti. Leira i suradnici također sugeriraju graničnu vrijednost PISA-e od $\geq$ $130,33 \mathrm{~mm}^{2}$ kao prediktora za prisutnost parodontitisa. U našem istraživanju vrijednosti PISA-e bile su se od 1248,6 do $2950,7 \mathrm{~mm}^{2}$. Te vrijednosti odgovaraju vrijednostima izračunatima za uznapredovali parodontitis (6).

Ograničenja ovog pilot-istraživanja su mala veličina uzorka i odsutnost kontrolne skupine. Zbog uzorka od $n=10$ koji predstavlja specifičnu populaciju pacijenata, tj. onih $s$ jakom upalom, uznapredovalim oblicima parodontitisa i prepoznatljivom intraoralnom halitozom, analiza nije zabilježila povezanost između svih parametara. Istraživanje će se nastaviti na većem uzorku, uključujući i kontrolnu skupinu pacijenata $s$ parodontitisom i bez halitoze.

\section{Zaključak}

Ovo pilot-istraživanje pokazuje i ponovno ističe složenu interakciju različitih čimbenika koji uzrokuju halitozu kod pojedinaca oboljelih od parodontitisa. Vrijednosti OLS-a povezane su s vrijednostima oralne higijene i naslaga na jeziku, no nije uočena povezanost $s$ dubinom sondiranja.

\section{Sukob interesa}

Autori nisu bili u sukobu interesa.

Doprinos autora: L. M. - primarni klinički istraživač, prikupljanje podataka, koncept i dizajn, interpretacija, vizualizacija, pisanje, odobravanje članka za objavljivanje; M. P. - koncept i dizajn, formalna analiza, statistička analiza, interpretacija, pisanje; J. P. - prikupljanje podataka, vizualizacija, pisanje; A. B. - interpretacija, pisanje, kritički osvrt; D. P. - nadzor, kritički pregled i uređivanje, odobravanje članka za objavljivanje; I. P. - operater kliničkog istraživanja, koncept i dizajn, interpretacija, pisanje, kritički pregled i uređivanje.

\section{Sažetak}

Cilj istraživanja: Halitoza ili zadah neugodan je vonj koji se širi iz usne šupljine. Česta je pritužba među pacijentima s parodontitisom, no njihova povezanost nije u cijelosti razjašnjena. Cilj ovog istraživanja bio je procijeniti povezanost između parametara halitoze, kliničkih parametara parodontitisa i obloženosti jezika te novog parametra - površine parodonta zahvaćene upalom (engl. periodontal inflamed surface area - PISA). Materijali i metode: U ovo su istraživanje uključeni podatci 10 pacijenata s parodontitisom i halitozom. Halitoza je procijenjena organoleptičkom metodom i prijenosnim sulfidnim monitorom kojim se mjere hlapljive sumporne spojeve. Proveden je sveobuhvatni parodontni pregled i registrirani su parametri dubine sondiranja, recesija gingive, razine kliničkoga pričvrstka, krvarenja pri sondiranju, plaka i naslaga na jeziku. PISA je izračunata koristeći se razinom kliničkoga pričvrstka, recesije gingive i krvarenja pri sondiranju. Rezultati: Uočena je povezanost između organoleptičke ocjene halitoze i obloženosti jezika $(r=0,554)$ i plaka $(r=0,614)$. Nije zabilježena povezanost između parametara halitoze i dubine sondiranja ili PISA-e. Organoleptička ocjena halitoze i vrijednost hlapljivih sumpornih spojeva značajno su korelirali $(r=0,931)$. Zaključak: Ovo pilot-istraživanje pokazuje i ponovno potvrđuje složenu interakciju između različitih čimbenika koji uzrokuju halitozu kod pacijenata s dijagnozom parodontitisa. Rezultati sugeriraju da naslage na jeziku i oralna higijena mogu biti važni u slučaju halitoze kod pacijenata s parodontitisom.
Zaprimljen: 1. ožujka 2021 Prihvaćen: 27. travnja 2021

Adresa za dopisivanje Larisa Musić, dr. med. dent. Sveučilište u Zagrebu Stomatološki fakultet Zavod za parodontologiju Gundulićeva 5, 10000 Zagreb, Hrvatska

+38514802219

Imusic@sfzg.hr

MeSH pojmovi: oralna higijena; jezik Ključne riječi: halitoza, parodontitis, jezik

\section{References}

1. Hasturk H, Kantarci A. Activation and Resolution of Periodontal Inflammation and Its Systemic Impact. Periodontol 2000. 2015 Oct;69(1):255-73.
2. Hujoel PP. Endpoints in periodontal trials: the need for an evidence-based research approach. Periodontol 2000. 2004 Oct;36(1):196-204. 
3. Newbrun E. Indices to measure gingival bleeding. I Periodontol. 1996 Jun;67(6):555-61.

4. Nesse W, Abbas F, van der Ploeg I, Spijkervet FKL, Dijkstra PU, Vissink A. Periodontal inflamed surface area: quantifying inflammatory burden. J Clin Periodontol. 2008 Aug;35(8):668-73.

5. Park S-Y, Ahn S, Lee J-T, Yun P-Y, Lee YJ, Lee JY, et al. Periodontal inflamed surface area as a novel numerical variable describing periodontal conditions. J Periodontal Implant Sci. 2017;47(5):328.

6. Leira Y, Martín-Lancharro P, Blanco J. Periodontal inflamed surface area and periodontal case definition classification. Acta Odontol Scand. 2018 Apr 3;76(3):195-8.

7. Nesse W, Linde A, Abbas F, Spijkervet FKL, Dijkstra PU, de Brabander EC, et al. Dose-response relationship between periodontal inflamed surface area and HbA1c in type 2 diabetics. J Clin Periodontol. 2009 Apr;36(4):295-300.

8. Susanto H, Nesse W, Dijkstra PU, Hoedemaker E, van Reenen YH, Agustina D, et al. Periodontal inflamed surface area and C-reactive protein as predictors of HbA1c: a study in Indonesia. Clin Oral Investig. 2012 Aug;16(4):1237-42.

9. Križan Smojver B, Altabas K, Knotek M, Bašić Jukić N, Aurer A. Periodontal inflamed surface area in patients on haemodialysis and peritoneal dialysis: a Croatian cross-sectional study. BMC Oral Health. 2020 Dec;20(1):95.

10. Iwasaki M, Taylor GW, Nesse W, Vissink A, Yoshihara A, Miyaza$\mathrm{ki} \mathrm{H}$. Periodontal disease and decreased kidney function in Japanese elderly. Am J Kidney Dis Off J Natl Kidney Found. 2012 Feb;59(2):202-9.

11. Susanto H, Nesse W, Kertia N, Soeroso J, Huijser van Reenen $Y$, Hoedemaker E, et al. Prevalence and severity of periodontitis in Indonesian patients with rheumatoid arthritis. J Periodontol. 2013 Aug;84(8):1067-74.

12. Quirynen M, Dadamio J, Van den Velde S, De Smit M, Dekeyser C, Van Tornout M, et al. Characteristics of 2000 patients who visited a halitosis clinic. J Clin Periodontol. 2009 Nov;36(11):970-5.

13. Tonzetich J. Production and Origin of Oral Malodor: A Review of Mechanisms and Methods of Analysis. J Periodontol. 1977;48(1):13-20.

14. Rosenberg M, Kulkarni GV, Bosy A, McCulloch CAG. Reproducibility and Sensitivity of Oral Malodor Measurements with a Portable Sulphide Monitor. J Dent Res. 1991 Nov;70(11):1436-40.

15. Persson S, Ediund M-B, Claesson R, Carlsson J. The formation of hydrogen sulfide and methyl mercaptan by oral bacteria. Oral $\mathrm{Mi}$ crobiol Immunol. 1990 Aug;5(4):195-201.

16. Plančak D, Musić L, Puhar I. Quorum Sensing of Periodontal Pathogens. Acta Stomatol Croat. 2015 Sep;49(3):234-41.

17. De Geest S, Laleman I, Teughels W, Dekeyser C, Quirynen M. Periodontal diseases as a source of halitosis: a review of the evidence and treatment approaches for dentists and dental hygienists. Periodontol 2000. 2016 Jun;71(1):213-27.

18. Yaegaki K, Sanada K. Volatile sulfur compounds in mouth air from clinically healthy subjects and patients with periodontal disease. J Periodontal Res. 1992 Jul;27(4 Pt 1):233-8.

19. Liu XN, Shinada K, Chen XC, Zhang BX, Yaegaki K, Kawaguchi Y. Oral malodor-related parameters in the Chinese general population. J Clin Periodontol. 2006 Jan;33(1):31-6.

20. Miyazaki H, Sakao S, Katoh Y, Takehara T. Correlation Between Volatile Sulphur Compounds and Certain Oral Health Measurements in the General Population. J Periodontol. 1995 Aug;66(8):679-84.

21. Morita M, Wang H-L. Relationship Between Sulcular Sulfide Level and Oral Malodor in Subjects With Periodontal Disease. J Periodontol. 2001 Jan;72(1):79-84.

22. Coli JM, Tonzetich J. Characterization of volatile sulphur compounds production at individual gingival crevicular sites in humans. J Clin Dent. 1992;3(4):97-103.

23. Armitage GC. Development of a classification system for periodontal diseases and conditions. Ann Periodontol. 1999 Dec;4(1):1-6.

24. Tonetti MS, Greenwell H, Kornman KS. Staging and grading of periodontitis: Framework and proposal of a new classification and case definition. J Periodontol. 2018;89(February):S159-72.

25. Seemann R, Conceicao MD, Filippi A, Greenman J, Lenton P, Nachnani $S$, et al. Halitosis management by the general dental practitioner--results of an international consensus workshop. J Breath Res. 2014 Mar;8(1):017101.

26. Greenman J, Lenton P, Seemann R, Nachnani S. Organoleptic assessment of halitosis for dental professionals-general recom- mendations. J Breath Res. 2014 Feb 24;8(1):017102.

27. MeSH Browser [database on the Internet]. Operating Instructions Halimeter®. [cited 2021 Jan 7]. Available from: https://www.halimeter.com/operating-instructions/

28. Rosenberg M, Septon I, Eli I, Bar-Ness R, Gelernter I, Brenner S, et al. Halitosis Measurement by an Industrial Sulphide Monitor. J Periodontol. 1991;62(8):487-9.

29. Winkel EG, Roldán S, Van Winkelhoff AJ, Herrera D, Sanz M. Clinical effects of a new mouthrinse containing chlorhexidine, cetylpyridinium chloride and zinc-lactate on oral halitosis: A dual-center, double-blind placebo-controlled study. J Clin Periodontol. 2003 Apr;30(4):300-6.

30. MeSH Browser [database on the Internet]. Gaus W. Interpre tation of Statistical Significance - Exploratory Versus Confirmative Testing in Clinical Trials, Epidemiological Studies, Meta-Analyses and Toxicological Screening (Using Ginkgo biloba as an Example). Clin Exp Pharmacol [cited 2021 Feb 20];05(04). Available from: https://www.omicsonline.org/open-access/ interpretation-of-statistical-significance--exploratory-versusconfirmativetesting-in-clinical-trials-epidemiological-studiesmetaanalyses-andtoxicological-screening-using-ginkgo-bilobaas-an-example-2161-1459-1000182. php?aid $=57026$

31. Rizzo AA. The possible role of hydrogen sulfide in human periodontal disease. I. Hydrogen sulfide production in periodontal pockets. Periodontics. 1967 Oct;5(5):233-6.

32. Tonzetich J. Oral malodour: an indicator of health status and oral cleanliness. Int Dent J. 1978 Sep;28(3):309-19.

33. Söder B, Johansson B, Söder PO. The relation between foetor ex ore, oral hygiene and periodontal disease. Swed Dent J. 2000;24(3):73-82.

34. Bosy A, Kulkarni GV, Rosenberg M, McCulloch CA. Relationship of oral malodor to periodontitis: evidence of independence in discrete subpopulations. J Periodontol. 1994 Jan;65(1):37-46.

35. Rosenberg M. Bad breath and periodontal disease: how related are they? J Clin Periodontol. 2006 Jan;33(1):29-30.

36. Calil C, Liberato FL, Pereira AC, de Castro Meneghim M, Goodson JM, Groppo FC. The relationship between volatile sulphur compounds, tongue coating and periodontal disease. Int J Dent Hyg. 2009 Nov; 7(4):251-5.

37. De Boever EH, Loesche WJ. Assessing the contribution of anaerobic microflora of the tongue to oral malodor. J Am Dent Assoc 1939. 1995 Oct;126(10):1384-93.

38. Bernardi S, Marzo G, Adelaide Continenza M. Dorsal Lingual Surface and Halitosis: a Morphological Point of View. Acta Stomatol Croat. 2016 Jun 15;50(2):151-7.

39. Yaegaki K, Sanada K. Volatile sulfur compounds in mouth air from clinically healthy subjects and patients with periodontal disease. J Periodontal Res. 1992 Jul;27(4):233-8.

40. Apatzidou AD, Bakirtzoglou E, Vouros I, Karagiannis V, Papa A, Konstantinidis A. Association between oral malodour and periodontal disease-related parameters in the general population. Acta Odontol Scand. 2013;71(1):189-95.

41. Vandekerckhove B, Van den Velde S, De Smit M, Dadamio J, Teughels W, Van Tornout $\mathrm{M}$, et al. Clinical reliability of non-organoleptic oral malodour measurements. J Clin Periodontol. 2009 Nov;36(11):964-9.

42. Kim D-J, Lee J-Y, Kho H-S, Chung J-W, Park H-K, Kim Y-K. A new organoleptic testing method for evaluating halitosis. J Periodontol. 2009 Jan;80(1):93-7.

43. Kozlovsky A, Gordon D, Gelernter I, Loesche W, Rosenberg M. Correlation between the BANA Test and Oral Malodor Parameters. J Dent Res. 1994 May;73(5):1036-42.

44. Tin-Oo MM, Yi Ying T, Saddki N, Ann Mani S. Self-Reported Halitosis among Medical, Dental and Health Science Undergraduate Students at the University Sains Malaysia. Acta Stomatol Croat. 2013 Jun 15:47(2):137-46.

45. Rosenauer T, Wagenschwanz C, Kuhn M, Kensche A, Stiehl S, Hannig C. The Bleeding on Brushing Index: a novel index in preventive dentistry. Int Dent J. 2017 Oct;67(5):299-307.

46. Socransky SS, Haffajee AD, Cugini MA, Smith C, Kent RL. Microbial complexes in subgingival plaque. J Clin Periodontol. 1998 Feb;25(2):134-44.

47. Torresyap G, Haffajee AD, Uzel NG, Socransky SS. Relationship between periodontal pocket sulfide levels and subgingival species. J Clin Periodontol. 2003 Nov;30(11):1003-10. 